\title{
Em Torno da Mesa: Alimentando Sensibilidades e Competências Relato de uma Experiência Educativa em Macau, RN, Brasil
}

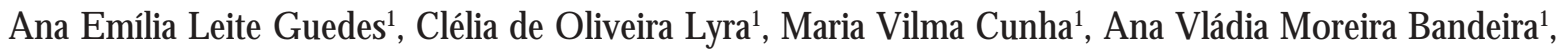 \\ Virginia Maria Cavalari Henriques ${ }^{1}$, Fernanda Barros Soares ${ }^{1}$, Laura Camila Pereira Liberalino ${ }^{1}$, Tereza \\ Marcelina D antas Vasconcelos ${ }^{1}$
}

O trabalho apresenta uma experiência educativa, realizada no projeto EM TO RNO DA MESA, dentro da temática de Segurança A limentar e Nutricional (SAN) em comunidades costeiras tradicionais, localizadas na Reserva de D esenvolvimento Sustentável Estadual Ponta do Tubarão, no município de Macau, Estado do Rio Grande do Norte (RN), Brasil. Com 0 objetivo de contribuir para otimização do aproveitamento do pescado e utilização dos subprodutos para possibilitar alternativas de produção para subsistência, o alimento para melhoria da saúde e a educação para autonomia, foram realizados encontros, oficinas pedagógicas, mostras, feiras e eventos do projeto EM TO RNO DA MESA, os quais foram espaços importantes de formação técnica e social e de desenvolvimento humano. D urante este processo, ocorreu a participação efetiva de 53 pessoas dessas comunidades. Nessa trajetória, foram revelados os princípios da SAN, mediante as boas práticas de manipulação do pescado, desde o mar até a mesa, e concretizado o ciclo positivo da produção, que incluiu as técnicas do beneficiamento ea comercialização de produtos alimentares à base de peixes de baixo valor comercial. A experiência tornou evidente anecessidade do fortalecimento da formação técnica e social, respeitando a cultura alimentar local, da otimização do arranjo da pesca artesanal e da busca de alternativas de comercialização na Reserva.

Palavras-chave: Segurança Alimentar e Nutricional, Educação Alimentar e Nutricional, D esenvolvimento Sustentável.

\section{At the table Nourishing sensibility and competence. Account of an educational experience in Macau, RN, Brazil}

This work reports an educational experience performed in the EM TO RNO DA MESA (at the table) project within the topic Segurança Alimentar e Nutricional (SAN) (Food and Nutrition Security). It was performed in traditional coastal communities of the Reserva de D esenvolvimento Sustentável Estadual Ponta do Tubarão (Ponta do Tubarão State Sustainable D evelopment Reserve), municipality of Macau, in the State of Rio Grande do Norte (RN), Brazil. In order to contribute to the optimization of fishing and the utilization of fisheries byproducts that simultaneously promote: subsistence production alternatives, health improvement of the community and food and education for self-government, meetings, educational workshops, exhibitions, fairs and events of the EM TO RNO DA MESA project were held, which were very important for technical training and human development. Fifty-three members of the local communities effectively participated in this endeavor. D uring the process, the principles of SAN were passed on through the knowledge of adequate practices in fish handling, from the sea to the table, demonstrating the positive production cycle that included beneficiating techniques through the commercialization of low trade value fish products. The experience demonstrated the evident need to strengthen technical

\footnotetext{
${ }^{1}$ Universidade Federal do Rio Grande do Norte (UFRN).
} 
know-how and social bonds, respecting the local food culture, while optimizing the elements of cottage fishing and to search for commercialization alternatives on the Reserve.

Keywords: Food and Nutrition Security, Food and Nutrition Education, Sustainable D evelopment

\section{Introdução}

O Projeto “EM TORNO DA MESA: alimentando sensibilidades e competências" foi uma exitosa experiência educativa, desenvolvida a partir da união de esforços entre 0 D epartamento de Nutrição da Universidade Federal do Rio Grande do Norte (UFRN), a Petrobrás, por meio do Programa Petrobrás Fome Zero (Edital 2004), e as comunidades costeiras tradicionais dos distritos de Barreiras, D iogo Lopes e Sertãozinho, município de Macau, Estado do Rio Grande do Norte, Brasil, para o combate à fome e garantia dos direitos sociais. O Projeto se constituiu como uma importante forma de implementação da responsabilidade social da Petrobrás. Por outro lado, as ações buscaram cumprir a missão da Universidade Federal do Rio Grande do Norte (UFRN), no âmbito da extensão universitária qualificada, ao desvelar possibilidades da formação profissional permanente, da garantia de acesso ao alimento de qualidade biológica e nutricional, da geração de trabalho e renda, do fortalecimento da pesca artesanal e da articulação institucional e comunitária.

O projeto foi formulado a partir da noção de soberania alimentar* ${ }^{1}$ como um Direito Humano à Alimentação ${ }^{2}$ e da sua concretização por meio da Segurança Alimentar e Nutricional** 3. Desde a sua concepção, o encaminhamento metodológico assumiu a dialogia e a transformação como referência para navegar.
Durante a fase de elaboração do Projeto, foi sugerido pelos moradores locais, como uma alternativa para geração de trabalho e renda, principalmente para as mulheres, 0 aprendizado de técnicas de beneficiamento do pescado. Além disso, a população revelou o interesse em conhecer formas de associar-se na busca de garantir a comercialização dos produtos do pescado beneficiado.

O resgate e a preservação da cultura alimentar local foram outra preocupação levantada pela equipe multidisciplinar, envolvida com o Projeto, composta por nutricionistas, pedagoga, técnicos em cooperativismo e bióloga. Nesse sentido, a universidade fortaleceu sua missão, no âmbito da extensão universitária, ao agregar profissionais de diferentes áreas em torno de um projeto coletivo do Departamento de Nutrição, para realizar um trabalho social de caráter propositivo.

Para o desenvolvimento das ações, importantes parcerias institucionais e locais foram concretizadas: Petrobrás, UFRN, Cooperativa Júnior Educacional do Rio G rande do Norte, Centro AMA GOA de Cultura e Meio Ambiente, Prefeitura de Macau, Comissão de Justiça e Paz, Igreja Católica, Conselho Gestor da Reserva de D esenvolvimento Sustentável Estadual Ponta do Tubarão (RD SEPT), Associação de Desenvolvimento Comunitário de Barreiras e Diogo Lopes. Essas parcerias se constituíram como um exitoso encontro entre instituições governamentais, organizações nãogovernamentais e a comunidade, para a realização de diálogos e reflexões sobre a noção de desenvolvimento sustentável que queremos.

Este trabalho encontra-se centrado na dialogia freireana ${ }^{4}$ e apoiado nas propostas da O rganização das Nações Unidas para a Educação, a Ciência e a Cultura (UNESCO ) relacionadas à educação ${ }^{5}$, quais

\footnotetext{
* Soberania A limentar significa "o direito dos povos de definir suas próprias políticas e estratégias sustentáveis de produção, distribuição e consumo de alimentos, que garantam o Direito Humano à Alimentação para toda a sua população, com base na pequena e média produção respeitando as próprias culturas e a diversidade dos meios pesqueiros de produção, comercialização e gestão dos espaços rurais, nos quais as mulheres desempenham um papel fundamental”. Fórum Mundial Sobre Soberania Alimentar. Havana (Cuba), 2001.

** A segurança alimentar e nutricional consiste na "realização do direito de todos ao acesso regular e permanente a alimentos de qualidade, em quantidade suficiente, sem comprometer o acesso a outras necessidades essenciais, tendo como base práticas alimentares promotoras de saúde que respeitem a diversidade cultural e que sejam ambiental, cultural, econômica e socialmente sustentáveis". CONSEA. Lei de Segurança Alimentar e Nutricional: Conceitos. Brasília: MS; 2006.
} 
sejam aprender a aprender, a fazer, a conviver com 0 outro e ser cidadão, tendo como referência 0 Direito Humano à Alimentação Saudável e Sustentável, com interesse em estabelecer um diálogo permanente com a comunidade. Concepção educacional dialógica e transformadora, contextualizada e problematizadora, com uma abordagem ética, enfatizando interconexões entre as dimensões biológica e cultural, foram rotas traçadas para o navegar da equipe do EM TORNO DA MESA.

Objetivou contribuir com a otimização do beneficiamento do pescado e utilização dos subprodutos, para possibilitar alternativas de produção para subsistência, o alimento para saúde e a educação para autonomia, uma vez que o município se constitui como grande produtor de pescado, sendo parte dele de baixo valor comercial (principalmente sardinha e peixe voador).

\section{Estratégias de Intervenção}

\section{A escolha do local e a tentativa de fazer acontecer}

Trocando opiniões, estabelecendo contatos e traçando rotas, 0 ancoradouro inicial foi a comunidade de Diogo Lopes, situada no município de Macau, distante $200 \mathrm{~km}$ de Natal (capital do Estado do Rio Grande do Norte). $\mathrm{O}$ fator relevante na escolha foi a fartura da produção pesqueira e a possibilidade de agregar valor ao produto, visando também à melhoria do consumo de peixe pela população. A região é uma das maiores produtoras de sardinha do Estado, porém não garante a sustentabilidade desta população, uma vez que o corre a ação de agentes intermediários, que adquirem o peixe in natura por um preço reduzido. O utro obstáculo ao consumo dos produtos oriundos da pesca é a manipulação que não atende às condições adequadas de procedimento, nem segue as orientações higiênico-sanitárias recomendadas pela vigilância sanitária ${ }^{6}$.

A agregação de trabalho e renda à atividade pesqueira pressupõe o fortalecimento de ações coletivas que promovam o associativismo e valorizem os talentos e a cultura da população, tendo a atividade educativa como elemento catalisador no desenvolvimento da autonomia e na preservação dos valores sociais de solidariedade, cooperação, respeito ao outro e a si mesmo ${ }^{7}$. Assim, visando otimizar 0 beneficiamento do pescado, foram propostas ações de capacitação, que tinham por base 0 conhecimento da realidade local, não perdendo de vista os indivíduos que dela iriam se beneficiar como sujeitos de suas ações e do seu conhecimento.

Para tanto, foram realizados estudos de diagnóstico por meio de entrevistas estruturadas e semi-estruturadas sobre o perfil socioeconômico e cultura alimentar. Por meio destes estudos, os participantes tiveram conhecimento da existência do projeto. Como estratégias pedagógicas, foram realizadas oficinas desenvolvidas com base no referido diagnóstico preliminar.

As oficinas pedagógicas, realizadas no período de 31 de agosto de 2005 a 15 de setembro de 2006, foram consideradas pela equipe como espaços de formação, de construção de reflexões e diálogos sobre Direito Humano à Alimentação Adequada, Segurança Alimentar e Nutricional, Beneficiamento de Pescado, Comportamento Alimentar, Culinária, Relações de G ênero, Cidadania e Meio Ambiente, Elaboração do Plano de Negócio e Constituição do Empreendimento Solidário. De todas as situações, participaram os pesquisadores e a comunidade. Os eventos do projeto "Em Torno da Mesa", seja a Mostra ou as Feiras de Produtos, apresentavam como objetivos principais a promoção, exposição e degustação dos produtos alimentares, com responsabilidade técnica (higiênica) e social. Portanto, durante todo o processo de formação nas oficinas, nos encontros e nos eventos, foi realizada a introdução de conceitos sobre os fundamentos do Direito Humano à Alimentação Adequada e da Segurança Alimentar e Nutricional.

Inicialmente, as oficinas aconteceram em espaços comunitários nos quais um dos desafios postos aos pesquisadores foi promover adequações físicas e operacionais para a sua realização, em concordância com as normas técnicas preconizadas pela vigilância sanitária de alimentos, em especial para a execução das oficinas de beneficiamento do pescado e culinária. A partir da inauguração do 
Rancho - Centro Petrobrás de Desenvolvimento Sustentável, espaço de formação técnica e social, patrocinado pela Lei Câmara Cascudo, legislação estadual de incentivo à Cultura e Petrobrás, o projeto teve suas atividades regulares realizadas neste espaço.

A prioridade no fazer foi a realização das oficinas pedagógicas, compreendendo-se que esta forma mobiliza no mesmo processo a teoria e a prática, integrando conceitos e procedimentos, além de fomentar atitudes positivas frente à vida. Quem faz explica, sabe explicar teoricamente o que faz, num processo que envolve dialeticamente indução e dedução.

Vale salientar que, devido à dimensão do projeto, optou-se por encaminhar ao Comitê de Ética em Pesquisa os trabalhos específicos que contemplassem as diversas áreas temáticas do projeto de extensão, recebendo posterior aprovação.

As ações do projeto "Em Torno da Mesa" refletiram o diálogo estabelecido com a comunidade desde a formulação inicial do projeto. 0 ponto de partida foi juntar-se, formar um grupo, depois definir as rotas e navegar. As teorizações brotaram do diálogo entre os saberes individuais interdisciplinares. Aprendeu-se a conviver com 0 outro, respeitando seus saberes e com eles estabelecendo sintonias, traçando rotas para navegar junto, seguir princípios direcionados em defesa do bem comum.

A proposta passou pela sensibilização das famílias, uma vez que a principal atividade econômica processava-se de forma grupal/ familiar, tendo as mulheres fundamental relevância na constituição da força de trabalho para a melhoria dos rendimentos familiares. Contribuiu, ainda, para a formação de valores e atitudes que buscaram resgatar os direitos e deveres de cidadania.

Não foi difícil identificar a força das mulheres da comunidade colocando-se à frente nos debates em defesa das causas sociais. Sentar para conversar nas calçadas, nos restaurantes e nas diversas associações locais foi a forma de unir e manter próximo do EM TORNO DA MESA as pessoas que buscavam o desenvolvimento autônomo e transformavam isso num sonho. Utilizou-se como recurso para a mobilização e sensibilização da comunidade a apresentação, em praça pública, do vídeo "(Vi)vendo a nossa história", no qual foram apresentadas as propostas do projeto. Este contou com a participação de atores locais e de pesquisadores, os quais teceram comentários sobre suas expectativas. Diversas autoridades participaram deste evento, colocando o projeto literalmente "na boca do povo!".

As rotas iniciais foram traçadas conforme 0 diagrama mostrado a seguir ${ }^{8}$ :

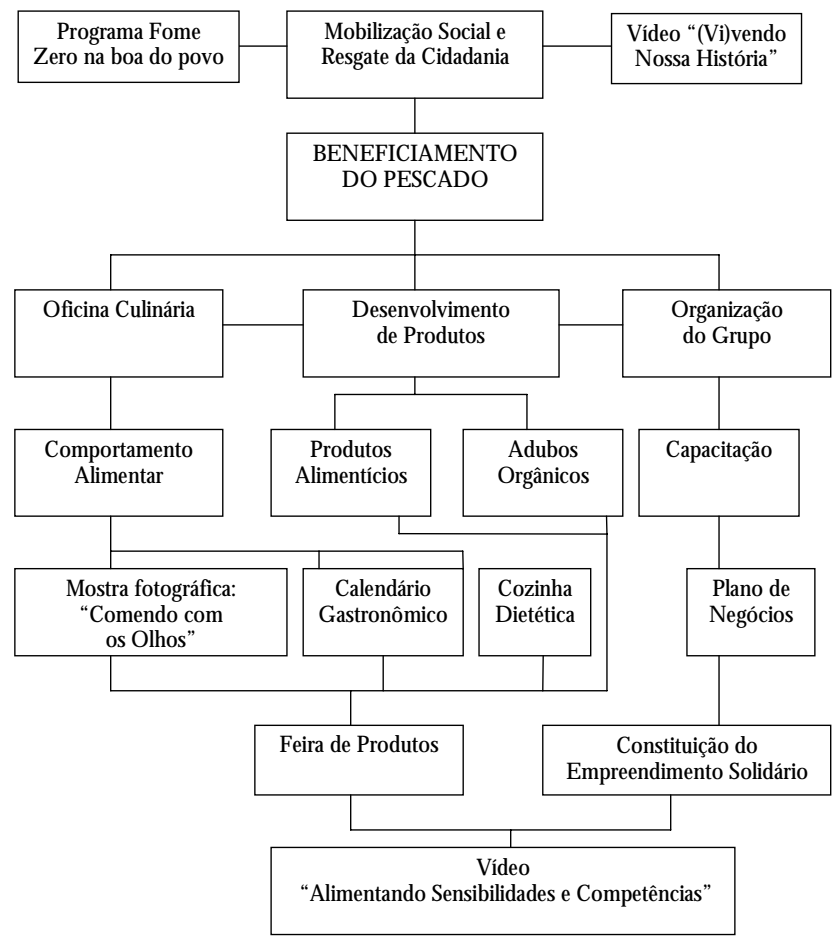

\section{Conhecendo a realidade}

Além da distância, havia um obstáculo à comunicação que era predominantemente realizada por meio de recados. Antecedendo as viagens e mesmo havendo o convite oral, havia a preocupação em fazê-lo por escrito, endereçado a cada participante, visando promover a inclusão de todos os alunos e alunas e proporcionar situações de leitura que pudessem dignificar e respeitar as pessoas, porque respeitam a sua leitura do mundo como ponte de libertação e autonomia de ser pensante e influente no seu próprio desenvolvimento. Tratavase de romper as dificuldades de leitura existentes, as quais podiam ser superadas com exercícios simples 
que, repetidos com freqüência, podiam transformarse em recurso para aprender a aprender.

Navegar criando rotas do saber sobre as águas de Barreiras, Diogo Lopes e Sertãozinho, por enquanto, orientadas por uma bússola que direcionava, entre outros, os seguintes pontos: estética, reconhecendo a identidade cultural e iniciando o diálogo com a Segurança Alimentar e Nutricional; respeito pelos saberes da comunidade, estabelecendo uma dialogia que vencesse as ações discriminatórias; reflexão voltada para o ato de saber dialogar; querer o bem para as pessoas, socializando os saberes sobre a alimentação adequada. Inclusive, vale salientar, que o nível de escolaridade não foi considerado como fator relevante para o processo de inclusão nas aprendizagens do EM TORNO DA MESA.

A compreensão de inclusão, que norteou as ações, permitiu o acolhimento de pessoas com diferentes graus de escolaridade e isto não se constituiu um obstáculo às aprendizagens quanto à alimentação adequada, nem na busca do desenvolvimento sustentável. Esta informação foi muito importante para que as oficinas acontecessem, de forma que os participantes do projeto facilmente entendessem o conteúdo desejado, otimizando assim os aprendizados. Isto também se constituiu em um exercício para os pesquisadores que refletiram e dialogaram sobre o processo de ensino e aprendizagem.

Considerou-se o saber de cada indivídio como um fator importante no processo de formação. Para as preparações culinárias, por exemplo, um conjunto de saberes já se encontra consolidado, ou seja, 0 conhecimento sobre o fogão, o modo correto de acendê-lo, como dosar a altura da chama conforme a especificidade de cada produto. Lidar com certos riscos que o fogo pode acarretar; planejar a compra de ingredientes mediante uma lista e até pesquisar os locais que os comercializassem com preços menores. A culinária tem um forte vínculo estético e faz-se necessário apresentar de modo que o olhar e 0 saborear sejam momentos de encantamento e prazer. Nas reuniões de aprendizagem sistemática, cada saber circulava e era bem vindo e refletido para tornar 0 profissional competente e acolhedor. Evidenciou- se que na prática se confirmavam, se modificavam ou se ampliavam estes saberes.

D essa forma, no "EM TORNO DA MESA" fragmentaram-se alimentos e reflexões, mas também uniram-se conceitos e preparações culinárias. Diversidade, inclusão, criatividade, compartilhar responsabilidades, saberes, decisões, alegrias e descobertas. Assim foi o navegar dos profissionais, que atuavam refletindo o horizonte metodológico que despontava para ser usado em cooperação.

A rota traçada na dialogia indicou propostas e modificações também nos conteúdos temáticos. Para as oficinas de comportamento alimentar e de culinária, os participantes escolheram as preparações que gostariam de elaborar junto com as pesquisadoras. 0 maior interesse manifestado pelos participantes do projeto foi utilizar receitas que envolvessem o peixe como ingrediente.

A perspectiva de inclusão, assumida desde 0 início, permitiu que três gerações de habitantes da Reserva de Desenvolvimento Sustentável Estadual Ponta do Tubarão (RD SEPT) participassem comunitariamente do mesmo processo, o que enriqueceu e tornou o fazer acolhedor.

A aproximação com a comunidade, a partir das trocas de sensibilidades, foi marcante para os participantes no seu navegar. A forma como as pessoas gostariam de ser chamadas constituiu-se em um importante elo com a comunidade, pois em alguns locais as pessoas são conhecidas pelos apelidos. Interessante foi notar que as pessoas gostavam de ser chamadas por meio da identificação da família (primeiro o nome da pessoa e, após, o nome do pai ou da mãe, conforme eram mais conhecidas na localidade, por exemplo: Maria (filha) de Antônio (pai) - traço cultural marcante da comunidade).

No decorrer das oficinas, procurou-se verificar a influência da pesca no consumo alimentar das pessoas da reserva, considerando os tipos de peixe mais abundantes na região e de baixo valor comercial (sardinha e peixe voador). Observou-se que havia um consumo significativo destes dois tipos de peixe. O utro ponto importante foi a identificação dos tipos de preparações culinárias elaborados com 
os peixes de baixo valor comercial. 0 prato de "sardinha na pressão" foi a preparação mais referida, seguida por preparações que empregavam o peixe voador como principal item culinário, sendo consumido assado, cozido e/ ou frito. O utras preparações envolvendo a sardinha também foram relatadas, tais como cozida, frita, integrante de bolinhos e consumida na forma de filé ${ }^{9}$.

O fazer culinário, evidenciado por meio do relato dos participantes em relação ao que eles sabiam fazer melhor, incluiu preparações à base de pescado, milho, hortaliças, carnes e ovos, doces e massas em geral. As preparações à base de pescado constituíram a maior proporção, seguida pela combinação arroz-feijão, docinhos, bolos e massas em geral ${ }^{9}$.

Os relatos referentes ao consumo alimentar na Reserva corroboram as evidências sobre a evolução da disponibilidade de alimentos no Brasil, indicando que a transição alimentar no país tem sido, de certo modo, favorável do ponto de vista dos problemas associados à subnutrição (aumento na disponibilidade de calorias per capita e ampliação da participação de alimentos de origem animal na alimentação) e desfavorável no que se refere à obesidade e às demais doenças crônicas nãotransmissíveis (aumento da participação na alimentação de gorduras em geral, gorduras de origem animal e açúcar e diminuição com relação a cereais, leguminosas e frutas, verduras e legumes) ${ }^{10}$.

\section{As ações de formação: do Direito Humano à Alimentação Adequada à Segurança Alimentar e Nutricional}

Partindo do pressuposto que a alimentação é um direito humano básico, parte integrante do direito à vida e uma prerrogativa para a cidadania, torna-se de fundamental importância a garantia dos princípios da Segurança Alimentar e Nutricional Sustentável ${ }^{2}$, desde 0 mar até a mesa do consumidor. Este é o desafio posto para os pesquisadores e para a comunidade costeira tradicional de Barreiras, D iogo Lopes e Sertãozinho ao considerarmos que a amplitude da SAN envolve desde a dimensão do acesso ao alimento, distribuição, comercialização até o seu consumo, utilização biológica e nutricional.
No presente trabalho, a dimensão do acesso foi verificada mediante o levantamento da participação da comunidade em programas sociais do governo, de organizações não- governamentais ou de organizações da sociedade civil. Para identificar o perfil de consumo dos alimentos, em especial do pescado, já que o Brasil apresenta um dos menores índices de consumo de pescado do mundo, foram construídos diálogos e reflexões sobre as práticas do comportamento alimentar da comunidade, o que possibilitou o delineamento preliminar de seu perfil nutricional.

0 perfil nutricional da comunidade é um reflexo do seu comportamento alimentar. Inclusive na comunidade da RD S Estadual Ponta do Tubarão foram reveladas, por meio de conversas com as pessoas, algumas práticas alimentares inadequadas. Estas práticas encontram-se representadas principalmente por preparações a base de peixe, apresentando elevado teor de gorduras saturadas pelo uso excessivo do leite de coco e cloreto de sódio.

É importante ressaltar que o peixe se constitui como a principal fonte de ácidos graxos do tipo ômega, que apresentam como principal função contribuir para a estabilização dos níveis de triglicerídeos no sangue ${ }^{11}$. 0 peixe é uma carne leve e saborosa. 0 pescado éum alimento de fácil digestão e fonte de proteínas, minerais, principalmente cálcio, fósforo, vitaminas A, D e Complexo B. 0 peixe se destaca por apresentar quantidade $21 \%$ a mais de aminoácidos essenciais do que a carne bovina ${ }^{12}$, bem como alta digestibilidade (97\% das proteínas são aproveitadas pelo organismo) ${ }^{13}$, credenciando-0 como um produto de alto valor biológico e nutricional.

A informação nutricional, associada à adoção de práticas alimentares saudáveis e adequadas, foi incentivada pelos pesquisadores e considerada por todos como elemento importante para a conquista da SAN. Além disso, a orientação e a educação alimentar e nutricional constituíram-se como ações de nutrição promotoras do direito humano à alimentação adequada, a médio e longo prazo.

Q uando se fala em Programa Fome Z ero, o que está 
na "boca do povo"? A equipe do EM TORNO DA MESA identificou, por meio de conversas informais, que a comunidade compreende que o Programa Fome Zero se resume ao Programa Bolsa Família, transferência direta de renda do governo federal para as famílias de baixa renda.

Porém, vale destacar que o Programa Fome Zero, implantado durante o primeiro mandato do Presidente Lula, contempla três conjuntos de políticas: 1) estruturantes, 2) emergenciais e 3) locais. Considerando que a ação do EM TORNO DA MESA se desenvolveu em uma comunidade costeira tradicional, na qual a pesca artesanal é a atividade econômica predominante, é importante destacar 0 papel desempenhado pelo Programa de Aquisição de Alimentos (PAA), parte integrante do Programa Fome Zero, vinculado ao Ministério do D esenvolvimento Social e Combate à Fome. Esta política de caráter estruturante tem como propósito promover a sustentabilidade econômica, ambiental e sócio-cultural dessas comunidades, por meio da aquisição da produção local, e posterior distribuição para outros programas sociais do governo, como por exemplo, Programa Nacional de Alimentação Escolar ("Merenda Escolar") e creches ${ }^{3}$. $\mathrm{Na}$ perspectiva da comercialização dos produtos EM TORNO DA MESA, o PAA, como parte integrante da rede de ações de segurança alimentar, pode se constituir uma importante opção.

\section{As ações de formação: o Beneficiamento do Pescado}

O objetivo específico desta oficina foi capacitar 60 pessoas de Diogo Lopes, Barreiras e Sertãozinho para a produção, com qualidade, de derivados do filé de peixe de baixo valor comercial, assim como os resíduos da filetagem. O s facilitadores eram nutricionistas, técnica especializada em alimentos do Instituto de Assistência Técnica e Extensão Rural (EMATER), professores e bolsistas do Curso de Graduação em Nutrição da UFRN. Foram realizadas seis oficinas, com no máximo 15 participantes cada uma, e carga horária (total) de 40 horas-aulas.

Os trabalhos foram distribuídos em duas etapas: (1) módulo teórico e (2) produção de lingüiça, quibe e hambúrguer de peixe. Durante as últimas oficinas, a produção dos referidos itens foi destinada aos eventos do EM TORNO DA MESA.

Importante ressaltar que foram realizadas adequações na formulação dos produtos elaborados com peixes de baixo valor comercial (sardinha, peixe voador e palombeta), com a finalidade de garantir a qualidade microbiológica e sensorial dos produtos alimentares. Os produtos foram desenvolvidos considerando sempre ingredientes necessários para $1 \mathrm{~kg}$ de pescado, para facilitar o cálculo da receita, conforme 0 número de porções ${ }^{9}$. A importância do registro das formulações encontra-se vinculada à necessidade da garantia da informação nutricional exata, pelos participantes da equipe do Projeto EM TORNO DA MESA, e subsídios para a respectiva rotulagem nutricional obrigatória dos produtos que serão posteriormente comercializados ${ }^{14}$.

A distribuição dos conteúdos teórico-práticos da $\mathrm{O}$ ficina de Beneficiamento de Pescado aconteceu em dois momentos distintos, para viabilizar a participação dos alunos e facilitadores da equipe do EM TORNO DA MESA. Para as duas etapas, os participantes foram eleitos para assumirem a liderança entre os membros do grupo (animador, memória de grupo, cronometrista, coordenador), com a finalidade de contribuir com a integração do grupo e dividir responsabilidades.

No módulo teórico foram abordadas questões referentes à importância do pescado na alimentação; boas práticas de manipulação de alimentos; cuidados com o pescado após captura e métodos de conservação.

No módulo prático foi realizada visita à cozinha do Rancho-Centro Petrobrás de D esenvolvimento Sustentável, para familiarização e demonstração de utilização, montagem, desmontagem e limpeza dos equipamentos. Em seguida, foram apresentados os procedimentos de retirada e estiramento das peles dos peixes, com posterior participação dos alunos. Procedeu-se a técnica de embalagem e conservação de acordo com cada produto.

As estratégias didáticas adotadas durante a 
oficina compreenderam: dinâmica para familiarização da nomenclatura utilizada pela área de microbiologia de alimentos; técnicas maiêuticas, que são dinâmicas de integração e relaxamento. Nos momentos de bioenergética (promoção de disposição para atividades), utilizou-se aulas expositivas dialogadas, cartazes, apostilas e demonstrações teórico-práticas.

Foi observada a participação ativa dos alunos, tanto no módulo teórico como no módulo prático. Ao final, todos organizavam o momento de degustação e avaliavam as preparações produzidas.

\section{As ações de formação: comportamento alimentar}

A equipe executiva das oficinas Em torno do comportamento alimentar... vivendo e aprendendo foi composta por duas professoras do D epartamento de Nutrição e uma aluna bolsista do projeto. Foram realizadas seis oficinas, que capacitaram 53 pessoas, com 8 horas de duração por turma.

O primeiro momento do evento foi dedicado ao resgate da oficina anterior "G ênero, Autogestão e Economia Solidária" na expectativa de estimular reflexões em torno da alimentação e do processo associativo.

Para refletir em torno da mesa os comportamentos alimentares, iniciou-se o diálogo partindo da apresentação das freqüências dos cinco alimentos mais lembrados, como sendo de consumo diário, e aqueles cujo consumo era eventual, além dos alimentos/ preparações que lembravam a infância e/ ou juventude, considerando diagnóstico prévio. A apresentação foi por meio de figuras/ fotos de alimentos/ preparações com o respectivo percentual, representando as principais escolhas alimentares. Foi dessa forma que, naturalmente, o grupo identificou outros comportamentos alimentares ${ }^{15}$ não revelados até então (uso de batata doce no feijão, que o almoço era a refeição mais realizada, a omissão do café da manhã, além de itens relacionados ao pré-preparo e ao preparo de alimentos, como por exemplo o arroz - lavar ou não, ser refogado ou escorrido, ser ou não enriquecido com hortaliças).

Foi uma ótima oportunidade para refletir sobre a primeira refeição do dia, sua importância e beneficio para o organismo e qualidade de vida. Outros comportamentos em torno da alimentação também ficaram evidentes, tais como: a fritura é a forma de preparo mais freqüentemente utilizada para o consumo de peixe; o cuscuz é consumido em qualquer uma das três principais refeições; a principal forma de consumo da farinha de mandioca parece ser através do preparo do pirão e suas variações.

Ao final da primeira parte da oficina, 0 objetivo era socializar os alimentos/ preparações trazidos pelos participantes para o primeiro lanche da tarde. Sendo a comida um dos símbolos de identidade cultural ${ }^{16}$, todos compartilharam, além dela, suas lembranças de infância e juventude, ao mesmo tempo que resgatavam valores tradicionais com respeito ao seu modo de viver. Foi nessa ocasião que, pela primeira vez, pudemos conhecer e degustar o arroz doce típico do local*, a cocada, o grude**, o bolo de milho, o anguzô***, além dos suspiros, tarecos**** e biscoitos com goiabada (embalados na forma de sanduíches).

Neste contexto, pode-se vivenciar o que Valente (2002) ${ }^{2}$ retratou quando referiu que ao alimentar-se junto de amigos, de sua família, consumindo preparações características de sua infância, de sua cultura, o indivíduo se renova em outros níveis, além do físico, fortalecendo, inclusive, a dignidade humana.

Foi possível perceber que, atualmente, o xerém não é mais produzido no núcleo familiar, mas adquirido devidamente industrializado nas pequenas

\footnotetext{
* O arroz doce é feito com arroz tipo agulhinha, cozido com leite de coco, e adição do açúcar queimado, erva doce, cravo e canela.

** 0 grude é uma espécie de bolo de goma ou massa de mandioca, com açúcar e coco, em geral assado, sendo, em alguns estados do nordeste, envolvido em folhas de bananeira.

*** $\mathrm{O}$ anguzô é uma preparação a base de xerém, leite de coco ou de vaca, podendo ser doce ou salgado.

**** Tareco é um tipo de biscoito caseiro de consistência firme, feito de farinha de trigo, ovos e açúcar. A massa é pingada na fôrma antes de assar dando-lhe um formato discóide. Faz parte da cultura popular na região Nordeste do Brasil.
} 
mercearias locais. Neste sentido, uma das participantes lembrou da influência da industrialização no comportamento alimentar, por meio das escolhas dos alimentos e até nas formas de adoecimento. A este respeito, foi possível identificar elementos da internacionalização dos hábitos alimentares, como a (des)ritualização da refeição, a simplificação e homogeneização dos processos culinários e dos alimentos servidos ${ }^{17}$.

Portanto, salienta-se que, do ponto de vista biológico, temos necessidades nutricionais e, do ponto de vista sociocultural, também temos necessidades a serem preservadas por meio da alimentação ${ }^{18}$.

No segundo momento da oficina, procedeuse à apresentação da pirâmide alimentar ${ }^{19}$, historiando sua concepção, revelando sua estrutura como um dos instrumentos utilizados nas práticas de educação nutricional, que contribuem para a escolha de uma alimentação saudável.

Nossa intenção, além de continuar refletindo os comportamentos alimentares, era também valorizar hábitos adequados e identificar comportamentos de risco em torno das práticas alimentares.

Foi com motivação e, de posse de cartões emborrachados com figuras dos alimentos mais lembrados (de uso diário), os participantes identificaram a ausência e/ ou freqüência reduzida de consumo de alguns grupos alimentares, tais como: leite e derivados, hortaliças e frutas. Ao mesmo tempo em que evidenciaram o almoço como refeição principal, os alimentos mais comumente presentes no café da manhã e/ ou no jantar foram menos referidos, embora para muitos deles os tubérculos, as gorduras e o grupo de açúcares e doces fossem também consumidos. Em seguida, todos os participantes receberam figuras emborrachadas dos demais grupos de alimentos, para posicionar adequadamente na pirâmide.

Posteriormente, cada grupo expôs suas reflexões em plenária, considerando as experiências alimentares e a proposta da pirâmide. Percebeu-se que a participação e o diálogo, gerados com entusiasmo e satisfação, foram contagiantes ao retratarem, de forma lúdica, seu cotidiano alimentar.

Por meio das discussões em torno dos produtos da cesta básica ocorreram reflexões sobre a segurança alimentar e nutricional, na perspectiva de disponibilidade, acesso físico e econômico aos alimentos. Ao observarem a composição da cesta básica de Natal $(\mathrm{RN}){ }^{20}$, com os respectivos preços unitários, foram descritos os produtos que não correspondiam à prática alimentar local e outros referidos como sendo de uso habitual. Além disso, compararam os preços praticados pelo comércio local e os preços de Natal. Os participantes concluíram que os preços locais eram mais elevados para os itens referentes a hortifrutigranjeiros, carne bovina e de frango, assim como leite e derivados. Além disso, outro importante aspecto levantado foi quanto às condições higiênico-sanitárias precárias de produtos de origem animal, referentes ao abate, transporte e armazenamento. Alguns participantes levantaram a questão da falta de uma política estruturada para estimular a produção e o consumo dos produtos hortifrutigranjeiros no local.

Estas reflexões foram alimentadas considerando as seguintes questões: (1) éfácil encontrar todos os alimentos que foram dispostos na pirâmidealimentar? (2) qual 0 austo provável das refeiōes analisadas? (3) œmo seria a aceitação na família?

Na discussão "Quando a questão é ter saúde o que está na "boca do povo"?, além das informações disponibilizadas quanto aos cuidados com a saúde e nutrição, enfocando as doenças carenciais e as crônicas não-transmissíveis (obesidade, cardiovasculares, diabetes e câncer), os participantes foram estimulados a identificar as atitudes que promovem a saúde e as atitudes de risco ${ }^{10}$. D e posse de dois cartões, sendo um verde e outro vermelho, cada participante revelava um comportamento relacionado com a cor do cartão, se 0 comportamento era ou não de risco para a saúde.

$\mathrm{Na}$ última parte da oficina, todos foram convidados para se dirigirem à cozinha do Rancho, onde foram disponibilizados gêneros alimentícios, como: frutas, leite, aveia, açúcar, rapadura, biscoitos, fubá, entre outros, que serviriam de base para a 
elaboração de um lanche que fosse considerado adequado pelo grupo. Nessa ocasião, a salada e 0 suco de frutas, além da papa de aveia, foram lembrados e elaborados com a participação de todos. Em seguida, houve a degustação e comentários.

Ao final da oficina, foi realizada a síntese do tema pelo resgate de conceitos que vêm sendo relacionados desde a primeira oficina, delineando caminhos... (vi)vendo o direito humano à alimentação adequada com segurança alimentar e nutricional.

\section{As Ações de Formação: Associativismo/ Cooperativismo}

As oficinas contemplavam conteúdos de cooperativismo e associativismo e tencionavam, por objetivo, despertar os participantes para 0 entendimento de todo o ciclo de formação de um grupo, com a finalidade de realizar um empreendimento coletivo, seja ele formal ou não, consolidando todas as etapas, desde os valores associativos/ cooperativos até a legalização do empreendimento propriamente dito. Foram realizadas oficinas com carga horária total de 60h, bem como assembléias e organização de eventos para a divulgação dos produtos do beneficiamento. Nestas oficinas, foram abordados os seguintes temas: relações de gênero, cidadania e meio ambiente, elaboração de Plano de Negócios e Empreendimento Solidário. Como facilitadores, contou-se com a colaboração de cinco pesquisadores, com formações distintas: cooperativismo, educação e nutrição.

Como estratégias metodológicas, foram utilizadas dinâmicas voltadas para a importância do associar-se, tomando como referência a questão da solidariedade na formação dos grupos de trabalho. Foram eleitos pelos participantes valores individuais e sociais que deveriam compor a base das relações humanas ${ }^{7}$.

O resultado mais significativo das ações do EM TORNO DA MESA foi a organização de grupos empreendedores locais, constituídos por pessoas capacitadas, que desejavam produzir e comercializar as preparações culinárias oriundas do pescado beneficiado, outras selecionadas na cultura local ou introduzidas pelas professoras do D epartamento de Nutrição da UFRN. Atitudes e depoimentos positivos foram revelados pelas comunidades quanto ao estabelecimento dos princípios da Segurança Alimentar e Nutricional na reserva.

Ressalta-se que a execução dessas ações de associativismo e cooperativismo contribuiu para 0 fomento e fortalecimento de uma cooperativa local, denominada Cooperativa de Pesca Artesanal e Beneficiamento de Pescado Ponta do Tubarão. Nesta cooperativa, estão incluídos os atores sociais envolvidos com a cadeia produtiva do pescado, inclusive beneficiadores capacitados pela equipe técnica do EM TORNO DA MESA. Sua finalidade foi viabilizar o processo de comercialização dos produtos alimentares e promover a geração de trabalho e renda na Reserva.

0 que o conhecimento científico explica é sempre uma experiência. Por isso, quem descreve 0 que vai explicar, descreve o que se tem de fazer para ter a experiência que se quer explicar. Diz-se que determinadas práticas culinárias podem garantir a SAN. Esta é uma explicação científica porque tem validade neste saber. Vivemos na sociedade do conhecimento sob a hegemonia da cultura que valoriza a ciência e a tecnologia. 0 conhecimento é um patrimônio humano que nutre o entendimento, a compreensão, e isto leva a uma ação harmônica e ajustada com os outros e o meio. 0 saber científico é operativo, apresenta-se como válido nas explicações que se constituem e se funda nas ações medidas que produzem resultados confiáveis e previsíveis para 0 nosso viver ${ }^{21}$.

As ações de formação do projeto EM TORNO DA MESA priorizaram os saberes sobre o pescado, pois as variedades de peixes são numerosas e de grande valor econômico por serem muito apreciadas no consumo humano e por suas características organolépticas particulares. Para fins nutricionais, é importante classificá-los pelo seu teor de gordura, especialmente pela presença e quantidade do ácido graxo $\alpha$-linolênico ( $\omega 3$ ), que pode interferir na saúde pela ação direta na resposta inflamatória ${ }^{11}$. 
Portanto, o conhecimento da origem, composição, formas de aquisição, preparo e armazenamento tornaram-se imprescindíveis para assegurar a qualidade e o consumo seguro. A etapa de beneficiamento teve como princípio 0 entendimento da cultura popular e 0 valor do peixe para a RD SEPT. Em todas as ações, que envolveram o contato entre os manipuladores e os alimentos, foram desenvolvidos os conteúdos sobre higiene e manipulação de alimentos, bem como as formas de conservação dos produtos obtidos mediante uma seqüência no processamento.

De outro modo, buscou-se o diálogo como fonte para a troca de saberes entre pessoas, diálogo entre as gerações, encontrando nesta troca as possibilidades para identificar e selecionar saberes importantes na história alimentar da comunidade da RD SEPT, para promover a socialização e continuidade desses saberes entre os jovens e, também, para que a equipe de pesquisadores fornecesse os instrumentos necessários para adicionar às preparações culinárias, oriundas da cultura histórica, os procedimentos adequados à SAN. Efetivou-se, assim, a completude da dialogia que moveu a formação EM TORNO DA MESA, fazendo uso das oficinas pedagógicas como solução para promover o diálogo entre teoria e prática.

0 objetivo final foi tornar permanente 0 processo de capacitação EM TORNO DA MESA para socializar os saberes da SAN.

\section{As Ações de Formação: Projetos Acadêmicos gerados}

O s resultados destas ações se encontram descritos em quatro monografias de conclusão de Curso de G raduação em Nutrição da UFRN, sendo que duas apresentaram estudos envolvendo seres humanos, tendo sido submetidas e aprovadas pelo Comitê de Ética em Pesquisa da Universidade Federal do Rio Grande do Norte, estando em fase de conclusão ${ }^{22,23,24,25}$.

Ao término das reflexões postas, foi possível (re)definir as rotas do EM TORNO DA MESA. As estratégias adotadas, os caminhos valorizados com a prática ${ }^{9}$, bem como o construir junto enriqueceram sobremaneira nosso modo de pensar e agir.

\section{Pelos Caminhos da Socialização: Os Limites do Possível}

O sonho do negócio próprio aproveitando os alimentos desperdiçados, uma proposta que poderia ser viável a partir das contribuições do projeto EM TORNO DA MESA: o substancial desperdício de parte da produção do pescado e sua comercialização também poderiam melhorar quando se agregasse valor comercial através do beneficiamento do produto.

É fato que a principal atividade econômica da RD SEPT processava-se de forma grupal/ familiar, tendo as mulheres fundamental relevância na constituição da força de trabalho para a melhoria da renda familiar, contribuindo, ainda, para a formação de valores e atitudes que resgatam os direitos e deveres de cidadania.

A cidadania ganhou destaque quando ações do EM TORNO DA MESA tomaram por referência que

"o direito à alimentação adequada realiza-se quando cada homem, mulher e criança, sozinho ou em companhia de outros, têm acesso físico e econômico, ininterruptamente, à alimentação adequada. Não deverá, portanto, ser interpretado em um sentido estrito ou restritivo, equacionado em termos de um pacote mínimo de calorias, proteínas e outros nutrientes específicos" ${ }^{2}$.

0 ato de alimentar-se, além de exercício de cidadania, também se constitui num ato de solidariedade. No caso da pesca, esta solidariedade manifesta-se da captura à mesa onde é consumida. No processo de formação do EM TORNO DA MESA, um momento interessante foi a realização de análises sensoriais com a população, quando a aceitação dos produtos alimentícios obtidos era verificada.

A nutrição humana acontece no reunir, no associar. Neste sentido, para gerar renda, o EM TORNO DA MESA buscou a forma associativa 
da sua organização por meio de um empreendimento solidário: cooperativa, associação, entre outros, que têm como princípio a autogestão para uma sustentabilidade social. Esse modo de agir teve início com o planejamento participativo, possibilitando assim o conhecimento coletivo da cadeia produtiva do pescado, propiciando 0 surgimento de novos projetos, tais como, reciclagem de materiais sólidos e reaproveitamento de outros materiais, os quais viriam a contribuir com 0 desenvolvimento sustentável e o fomento do mercado justo esolidário.

As dificuldades para escoar a produção exigiram um diagnóstico participativo sobre as demandas locais e regionais, bem como das necessidades e potencialidades para a construção de uma estratégia de comercialização e promoção do trabalho desenvolvido no plano de negócio dos trabalhadores.

A definição do tipo de empreendimento seguiu os critérios de uma organização de caráter solidário de forma a permitir a sua autogestão. 0 objetivo foi incentivar a produção, a comercialização e a formação de grupos empreendedores, que atuassem de forma solidária na geração de renda, e construir um empreendimento solidário que promovesse a cidadania por meio do efetivo exercício dos direitos do trabalho.

\section{Conclusões}

Podemos dizer que a experiência foi muito rica e que exercitou-se a possibilidade de realizar uma educação mais solidária e "plantar sementes" em outras pessoas, da mesma forma que fomos tocados pelos sonhos delas. As pessoas muito nos ensinaram com sua disposição em participar desta experiência educativa, que promoveu possibilidades de uma profissionalização como beneficiadores de pescado. Os resultados serão disponibilizados para as instituições parceiras e para a comunidade da reserva, considerando que ações de continuidade podem ser implementadas, visando um desenvolvimento sustentável em consonância com os desejos e valores culturais da comunidade da RD S Estadual Ponta do Tubarão.
Continuar o processo de formação, elevar a auto-estima dos participantes, difundir as idéias associativistas, promover a consolidação da Cooperativa de Pesca Artesanal e Beneficiamento de Pescado Ponta do Tubarão, otimizar 0 beneficiamento do pescado e a cadeia produtiva da pesca artesanal na reserva, promover a certificação dos produtos da pesca, apoiar a reflexão sobre a cultura alimentar, criar e buscar a sustentabilidade dos grupos empreendedores de produção e beneficiamento do pescado e unir as pessoas de Barreiras, Diogo Lopes e Sertãozinho são desafios postos à equipe do EM TORNO DA MESA.

Vale registrar também que a rede ainda não se encontra concluída. Porém, as opiniões e decisões direcionam para a continuidade e ampliação das ações, que já abrangem toda a área da reserva e fortalecem a atividade pesqueira. Manter o processo de formação sobre beneficiamento de pescado e preparações culinárias, visando agregar valor aos peixes de baixo valor comercial, continua sendo 0 desejo da população, que agora se estende às demais comunidades da reserva. Por outro lado, soma-se a concretização do sonho de constituir e gerenciar, utilizando a forma do associativismo, na busca do empreendimento solidário - uma Unidade de Beneficiamento de Pescado na RD S Estadual Ponta do Tubarão.

\section{Referências Bibliográficas}

1. Soberania Alimentar: É possível garantir a Soberania Alimentar no mundo de hoje? / O pinião Agroecologia e D esenvolvimento Rural Sustentável 2: (4); 2001.

2. Valente FLS. Direito Humano à Alimentação: desafios e conquistas. São Paulo (SP): Cortez; 2002.

3. Brasil. Ministério da Saúde. Secretaria de atenção à Saúde. Departamento de atenção Básica. Coordenação-Geral da Política de Alimentação e Nutrição. Estudo de Caso Brasil: a integração das ações de alimentação e nutrição nos planos de desenvolvimento nacional para o alcance das metas do milênio no contexto do Direito Humano à Alimentação. Brasilia (DF): Ministério da Saúde. [Série G. Estatísticas e Informação em Saúde]; 2005. 303p. 
4. Freire, P. Pedagogia da Autonomia: saberes necessários a prática educativa. São Paulo (SP): Paz e Terra [Coleção Leitura]; 1997.

5. Delors J. Educação: um tesouro a descobrir. $6^{\text {nd }}$ ed. São Paulo (SP): Cortez; Brasília (DF): UNE SCO ; 2001.

6. Regulamento Técnico de Procedimentos Operacionais Padronizados aplicados aos Estabelecimentos Produtores/ Industrializadores de Alimentos e a Lista de Verificação das Boas Práticas de Fabricação em Estabelecimentos Produtores/ Industrializadores de Alimentos. Resolução RDC 275 [21 de outubro de 2002]. D OU [23 de outubro de 2003].

7. Singer, P. A recente ressurreição da economia solidária no Brasil. In: Santos BS. Produzir para viver: os caminhos da produção não capitalista. Rio de Janeiro (RJ): Civilização Brasileira; 2002. p.83 - 129.

8. Relatório Parcial de Extensão Universitária do Projeto EM TORNO DA MESA: alimentando sensibilidades e competências. Natal $(R N)$ : D epartamento de Nutrição/ UFRN; 2005.

9. Relatório Final de Extensão Universitária do Projeto EM TORNO DA MESA: alimentando sensibilidades e competências. Natal (RN): D epartamento de Nutrição/ UFRN; 2006.

10. Brasil. Ministério da Saúde. Análise da Estratégia G lobal para Alimentação Saudável, A tividade Física e Saúde. D ocumento realizado pelo grupo técnico assessor instituído pela Portaria do Ministério da Saúde nํ5 596, de 8 de abril de 2004.

11. Ettinger S. Macronutrientes: Carboidratos, Proteínas e Lipídeos. In: Mahan LK; Escoott-Stump S. Alimentos, Nutrição \& D ietoterapia. São Paulo (SP): Roca; 2005. p. 35-71.

12. O gawa ELMM. Manual de Pesca. São Paulo (SP): Livraria Varela; 1999.

13. Tirapegui J, Castro IA, Rossi L. Biodisponibilidade de Proteínas. In: Cozzolino, SMF. Biodisponibilidade de Nutrientes. Barueri (SP): Manole; 2005. p. 67-123.
14. Brasil. Ministério da Saúde. Agência Nacional de Vigilância Sanitária. Rotulagem nutricional obrigatória: manual de orientação aos Consumidores de Alimentos. Brasília: Ministério da Saúde / Universidade de Brasília; 2005. 17p.

15. Souza MDCA, Hardt PP. Evolução dos hábitos alimentares no Brasil. Rev Brasil Alimentos [internet] 2002 [citado 2007 out 18]; 15. Disponível em: www.brasilalimentos.com.br/ BA/ pdf/ 16/ 16\%20-\%20Habitos\%20Alimentares

16. Maciel ME. Identidade Cultural e Alimentação. In: Canesqui AM, Garcia RWD. Antropologia e Nutrição: um diálogo possível. Rio de Janeiro (RJ): Editora Fiocruz; 2005. p. 49-55.

17. Franco A. O alimento no século XX: a internacionalização. A McD onaldização. In:

D e caçador a gourmet: uma história da gastronomia. $3^{\text {nd }}$ ed. São Paulo (SP): SENAC; 2001. p. 229-257.

18. Daniel JMP, Cravo VZ. Valor Social e Cultural da Alimentação. In: Canesqui AM, Garcia RWD. Antropologia e Nutrição: um diálogo possível. Rio de Janeiro (RJ): Editora Fiocruz; 2005. p. 57-68.

19. Brasil. Ministério da Saúde. Secretaria de A tenção à Saúde. Coordenação-Geral da Política de Alimentação e Nutrição. Guia Alimentar para a população brasileira: promovendo a alimentação saudável. Brasília: Ministério da Saúde. [Série A: Normas e Manuais Técnicos]. 210p.

20. Brasil. D epartamento Intersindical de Estatística e Estudos Socioeconômicos. Pesquisa Nacional da Cesta Básica. [internet] 2006 Jan-Mar. [citado 2006 Mar 5]. D isponível em: http:/ / www.dieese.org.br/ $\mathrm{rel} / \mathrm{rac} / \mathrm{cesta.xml}$.

21. Monteiro S, Vargas E [org.]. Educação, comunicação e tecnologia educacional: interfaces com o campo da saúde. Rio de Janeiro: Editora Fiocruz; 2006.

22. TAVARES PJC. Os Saberes EM TORNO DA MESA: Lições de Segurança A limentar e Nutricional na Reserva de D esenvolvimento Sustentável Estadual Ponta do Tubarão.[Projeto de Trabalho de Conclusão 
de Curso de Graduação em Nutrição]. Natal: Departamento de Nutrição - Universidade Federal do Rio Grande do Norte; 2006.

\section{BARROS MRF. EM TORNO DA MESA: O} resgate dos hábitos alimentares regionais, pelos princípios da Técnica D ietética. [Projeto de Trabalho de Conclusão de Curso de Graduação em Nutrição]. Natal: Departamento de Nutrição Universidade Federal do Rio Grande do Norte; 2006.

24. MARQUES CO. Q ualidade Microbiológica de Produtos a Base de Peixe de Baixo Valor Comercial. [Projeto de Trabalho de Conclusão de Curso de Graduação em Nutrição]. Natal: D epartamento de Nutrição - Universidade Federal do Rio Grande do Norte; 2006.

25. MEDEIROS MCS. Estabilidade Oxidativa de Produtos Elaborados a partir de Peixes de Baixo Valor Comercial. [Projeto de Trabalho de Conclusão de Curso de Graduação em Nutrição]. Natal: D epartamento de Nutrição - Universidade Federal do Rio Grande do Norte; 2006.

\section{Autores}

Ana Emília Leite Guedes - D outora em Saúde Coletiva pela Universidade do Estado do Rio de Janeiro (UERJ). Professora Adjunta IV do D epartamento de Nutrição da Universidade Federal do Rio Grande do Norte (UFRN)

Correspondência: Rua Alberto Maranhão, 968/ 1500 Tirol - CEP 59020-330 - Natal/ RN

Clélia de Oliveira Lyra - Professora Assistente I do Departamento de Nutrição da UFRN.

Maria Vilma Cunha - Professora Aposentada da UFRN.

Ana Vládia Moreira Bandeira - Professora Adjunta I do Departamento de Nutrição da UFRN.

Virginia Maria Cavalari Henriques - Professora Substituta do D epartamento de O ceanografia e Limnologia da UFRN.

Fernanda Barros Soares - G raduanda do Curso de Nutrição Universidade Federal do Rio Grande do Norte(UFRN).

Laura Camila Pereira Liberalino - Nutricionista (UFRN), Especialista em Saúde da Família(EFSFVS).

Tereza Marcelina D antas Vasconcelos - Graduanda do Curso de Aquicultura Universidade Federal do Rio Grande do Norte (UFRN).

Recebido em: 03/ 01/ 2007

Aceito em: 18/ 02/ 2008 